\title{
BMJ Open Determinants of adolescents' perceptions on access to healthcare services in the Kingdom of Saudi Arabia: Jeeluna national survey findings
}

Shahenaz Najjar (1) , ${ }^{1,2}$ Mayssa Saade, ${ }^{3}$ Sahar Abdalla, ${ }^{2,4}$ Fadia AlBuhairan ${ }^{2,5,6}$

To cite: Najjar S, Saade M, Abdalla S, et al. Determinants of adolescents' perceptions on access to healthcare services in the Kingdom of Saudi Arabia: Jeeluna national survey findings. BMJ Open 2021;11:e035315. doi:10.1136/ bmjopen-2019-035315

- Prepublication history for this paper is available online. To view these files, please visit the journal online (http://dx.doi. org/10.1136/bmjopen-2019035315).

Received 04 November 2019 Revised 14 October 2020 Accepted 19 0ctober 2020
Check for updates

(C) Author(s) (or their employer(s)) 2021. Re-use permitted under CC BY-NC. No commercial re-use. See rights and permissions. Published by BMJ.

For numbered affiliations see end of article.

Correspondence to Dr Shahenaz Najjar; shnajjar@gmail.com and Dr Fadia AlBuhairan; fadia.albuhairan@gmail.com

\section{ABSTRACT}

Objectives The study aimed at identifying the determinants of adolescents' access to healthcare services.

Setting Intermediate and secondary schools across all 13 regions in the Kingdom of Saudi Arabia (KSA) from 2011 to 2012 through the Jeeluna national school-based survey.

Participants Intermediate and secondary school students participated in the study. A multistage, cluster, random sampling technique was used. Participants responded to a self-administered questionnaire that addressed several domains.

Main outcome measure Adolescents' perception of access to healthcare services.

Results Twenty-five per cent of participants reported difficulty in accessing healthcare. Women, early (younger) adolescents and adolescents with three siblings were less likely to report difficulty in accessing healthcare than men, late (older) adolescents and those with fewer than three siblings. Adolescents from low-income families and those with either mental or physical illness were more likely to report difficulty in accessing healthcare than adolescents from higher income families and those without mental or physical illnesses.

Conclusions Disparities in access to care exist between certain subpopulations of adolescents. Efforts are needed to support enhancing access and making it more equitable. Training for healthcare professionals and targeted health policies are necessary to improve adolescents' access to health services in the KSA.

Trial registration number RC08-092; King Abdullah International Medical Research Centre.

\section{INTRODUCTION}

Access to healthcare is vital in providing individuals with opportunities to maintain their mental and physical well-being as well as their quality of life. The US Institute of Medicine defines access to health services as a 'broad set of concerns that centre on the degree to which individuals and groups are able to obtain needed services from the medical care system'. 'Several concerns should be taken into consideration when dealing with access to healthcare services such as supply
Strengths and limitations of this study

- This is the first study to assess access to healthcare services from an adolescent's perspective.

- This is the first study that addresses the determinants of healthcare access among adolescents at a national level in Saudi Arabia.

- The large sample size $(\mathrm{N}=12$ 575) with adequate quality of data created good evidence to inform health ministry/government and healthcare service providers when targeting interventions to improve adolescents' accessibility to health services.

- Limitations included not having the ability to differentiate between accessibility of community versus clinical healthcare settings.

- Our study was cross-sectional in nature, and, as such, causality cannot be inferred.

and demand as main characteristics, equitable healthcare and ensuring equal access to healthcare especially for vulnerable groups. ${ }^{23}$ Poor access to care has pronounced effects on the health and well-being of individuals and society. Monitoring the accessibility of healthcare is essential in order to increase awareness of the challenges being faced, assign responsibility to those involved in improving access to health services and ensure equal access to healthcare across different age groups and populations.

Adolescent health is gaining global attention due to the increasing knowledge about the opportunities presented to young people. The age range of this group encompasses the period of development corresponding to the ages of 10-19 years. ${ }^{4}$ This age group is generally the healthiest in each society. However, recent efforts in adolescent health research have shed light on several important public health and social problems, which peak during this developmental period. ${ }^{5-7}$ Adolescents need access to health services for a variety of reasons: mental health and 
emotional problems, substance use, risk-associated sexual behaviours and other health risk behaviours, ${ }^{8}$ in addition to chronic diseases and annual preventive check-ups. ${ }^{9}$ Their rapid and dynamic growth involves physical, intellectual, emotional and social development. ${ }^{10}$ Their needs from the healthcare system are much more complex than that of children or adults, and, unfortunately, these needs often go unnoticed. Healthcare access for adolescents involves both 'child' and 'adult' facilities, since services dedicated to adolescents are often unavailable, despite the body of literature recommending the need for such. ${ }^{911}$ As such, an adolescent may be overage or underage for the local facility where the most appropriate care to meet his/her medical needs can be found. ${ }^{12}$

Accessibility of adolescent health services has been discussed through different frameworks globally. This topic can be approached either by addressing the demographic characteristics such as family size, and the family's ability to provide the adolescent with the needed services (ie, through health insurance and transportation) or by assessing the need to reach the healthcare services (ie, diagnosis, previous symptoms and emergency). ${ }^{8}$ The WHO shows that inequity in health delivery among adolescents is related to the social determinants of health (ie, the conditions in which people are born, grow and live).$^{13}$

The national healthcare system in the Kingdom of Saudi Arabia (KSA) provides healthcare services through both government and private agencies. The role of the private sector in the provision of healthcare services is growing steadily. The Ministry of Health is the main provider of healthcare in the KSA, with a total of 462 hospitals and 2282 primary healthcare centres, ${ }^{14}$ providing about $60 \%$ of health services in the country. The remaining health services are provided either by other government agencies or the private sector. The 2030 Saudi Vision, developed in 2016, highlights new health reforms, including enhancing the quality and safety of healthcare services as well as ensuring access to healthcare and reducing waiting times across all stages of service delivery. ${ }^{15}$ Despite rapid developments in the Saudi healthcare system, a shortage of services for adolescents remains. ${ }^{141617}$ Furthermore, healthcare services in the KSA predominantly focus on child or adult health, with the age cut-off between those two groups being 12-14 years. This further aggravates the problem of unmet needs for adolescents, since there is often a gap between the training given to healthcare providers and the needs of adolescent patients. ${ }^{16}$

A national study called Jeeluna was conducted to assess the health status and needs of adolescents in the KSA. Preliminary findings revealed difficulties in accessing health services for one out of every four adolescents surveyed. ${ }^{6}$ Building on these findings, to the best of our knowledge, the current study is the first to address the determinants of healthcare access among adolescents at a national level in the KSA. The objective of the study described herein was to identify the determinants of such access from a social, economic and health status point of view. Understanding such a relationship will contribute to building the necessary database that policy and decisionmakers can rely on when targeting interventions. ${ }^{18}$

\section{METHODS}

\section{Study design}

'Jeeluna' (Arabic for 'our generation') was a crosssectional, school-based survey conducted in 2011-2012 with students from intermediate and secondary schools across all 13 regions of the KSA. We used the database from this survey to achieve our study objectives. The study was approved by King Abdullah International Medical Research Centre as well as the KSA's Ministry of Education.

\section{Jeeluna methodology}

The Jeeluna survey was carried out using a multistage, stratified, cluster random sampling technique. The country was divided into 13 administrative regions, each with multiple school districts (including rural and urban districts). Sampling was stratified by district, school level (intermediate and secondary schools) and gender of the school, since schools are gender segregated. Classes within the selected schools were randomly selected; evening schools and schools for special need students were excluded from the randomisation. All students within the selected classes were invited to participate in the study. An informational letter was sent to parents, together with consent and assent forms. The consent and assent forms were signed by parents and students, respectively. Data were collected through a self-administered questionnaire addressing access to health services. A detailed methodology of Jeeluna was published in $2015 .^{6}$ The Jeeluna survey was based on the Youth Risk Behavior Survey and the Global School-based Student Health surveys. The final questionnaire, after adaption to the KSA context and culture, included the following 11 domains: (1) family, (2) education/schooling, (3) nutrition/dietary behaviours, (4) activities, including physical activity and technology use (sedentary activity), (5) safety, (6) sleep, (7) violence and bullying, (8) tobacco and substance use (including alcohol use), (9) health, (10) health services and (11) health knowledge. The domains of relevance to our study are health and health services as well as socioeconomic factors. Access to healthcare services was measured on a 4-point Likert scale; the responses were dichotomised, so that 1 (very difficult) and 2 (difficult) were categorised as difficult and 3 (easy) and 4 (very easy) were categorised as easy to access healthcare. Other variables measured related to access included: last visit to a doctor (less than 3 months ago, within the last 3-6 months, more than 6 months ago), annual check-up (no/ yes) and effectiveness of access that was assessed with the question 'Did your physician spend enough time and listen to you at your last visit?'(no/yes).

The study also measured adolescents' health status by self-reported questions on having chronic diseases, 
depression or anxiety. Depression and anxiety were categorised according to symptoms present always, most of the time, sometimes, rarely or never. Adolescents who responded most of the time or always were considered depressed or anxious. These two variables were regrouped into one variable called mental health, where adolescents were considered as having mental health problems when they were depressed or anxious or both.

For investigating sociodemographic and economic characteristics, data were collected on age, gender, father's/mother's educational level, region (urban and rural and the 13 administrative regions of KSA), family size and overall family income (less than US\$2500, between US $\$ 2500$ and US $\$ 4000$, more than US $\$ 4000$ ).

\section{Patient and public involvement}

No patients were involved.

\section{Statistical analysis}

Raw data were processed in accordance with best practices for raw data management to identify any inaccuracies or incompleteness before performing the statistical analysis. Data were weighted to account for the probability of selection of students within each school, and the probability of selection of schools, stratified by gender and level (intermediate and secondary), within each district. Results were reported in terms of frequency, weighted frequency, percentage and SE of percent.

Univariate analysis was carried out to quantify the adolescents' socioeconomic characteristics and their perception of access to healthcare. The multivariate model was limited to the covariates that showed significance at the bivariate level (age, gender, number of siblings, income, mental health, chronic illness, time spent with physician at last visit, annual health check-up); $p$ value $<0.05$. Binary logistic regression was used to determine the predictors of access to healthcare among adolescents. Results were reported in terms of OR, SE, 95\% CI and $p$ value. Significance was declared at alpha less than 0.05. All analyses were carried out using SAS V.9.4; SAS Institute, Cary, North Carolina, USA.

\section{RESULTS}

\section{Descriptive statistics of participants}

A total of 12575 adolescents participated in the Jeeluna survey, giving a student response rate of $32.7 \%$. The sample contained comparable numbers of men and women. Most of the sample fell into the age range of $13-15$ years $(43 \%)$ or $16-18$ years $(50 \%)$. Approximately $50 \%$ of fathers and $40 \%$ of mothers had a high school education or higher. Fifty per cent of the sample reported the overall family income as less than US\$2500 monthly. Overall, the sample of adolescents was healthy with neither chronic disease (91\%) nor mental health problems (83\%). Twenty-four per cent of the adolescents rated their access to healthcare as difficult. Sixty per cent of the adolescents surveyed had visited a healthcare provider in the previous 3 months, and only $32 \%$ of them had received an annual check-up. Thirty-nine per cent of those who had visited a doctor reported insufficient time spent with the physician at their last visit. Further details of the results obtained are presented in table 1.

\section{Associations between access to healthcare, sociodemographic and socioeconomic characteristics and health status}

Our results revealed that age $(\mathrm{p}=0.032)$, gender $(\mathrm{p}=0.021)$, number of siblings $(\mathrm{p}<0.0001)$ and household income $(\mathrm{p}<0.0001)$, mental/physical health $(\mathrm{p}<0.0001)$, time spent with physician $(\mathrm{p}<0.0001)$ and annual check-ups $(p<0.0001)$ were significant predictors of access to healthcare. A binary logistic regression model revealed that women and early adolescents (10-14 years of age) were $20 \%$ less likely to report difficulties in accessing healthcare compared with men and late adolescents (15-19 years of age), respectively. No overall regional differences in perceptions about access to healthcare were observed ( $>0.05)$. Adolescents with three siblings were 56\% less likely to report difficulties in accessing healthcare compared with adolescents with no siblings. Adolescents from low-income households were $81 \%$ more likely to report difficulties in accessing healthcare than those from high-income families. Adolescents with either mental or chronic illness were $58 \%$ and $70 \%$ more likely to report difficulties in accessing healthcare. Further details are presented below in table 2 .

\section{DISCUSSION}

Our findings raise awareness of adolescents' healthcare access problems. Collectively, the determinants we identified suggest that there is a great need to enhance the existing health services for adolescents in the KSA. The results revealed that one in four adolescent students reported access to healthcare as being difficult in the KSA. More attention and interventions should be implemented for this specific age group, with a focus on the more vulnerable subpopulations of adolescents to reduce the inequities among adolescents overall.

Consistent with other studies, adolescents from lowincome households perceived more difficulties in accessing healthcare compared with adolescents from high-income families. ${ }^{19-21}$ Adolescents from low-income families are usually lacking the financial and protective social supports enjoyed by adolescents from high-income families. Almost half of the adolescents surveyed in this study came from low-income families, but since health services in the KSA are universally provided to citizens, the cost of accessing healthcare is unlikely to be a primary factor in ease of access. Other factors related to socioeconomic status, such as transportation issues, increased work demands of parents as well as supply of accessible health services to this population, may be impacting adolescents' access to care. Since the majority of adolescents are schoolgoing, ${ }^{22}$ providing and promoting adolescent health 
Open access

Table 1 Participant characteristics

\begin{tabular}{lcccc}
\hline Variable & Frequency & Weighted frequency & Percent & SE of percent \\
\hline Gender & & & & \\
$\quad$ Male & 6444 & 1053466 & 50.49 & 1.39 \\
Female & 6098 & 1032818 & 49.51 & 1.39 \\
$\quad$ Total & 12542 & 2086283 & 100.00 & \\
Age groups & & & & \\
Early adolescent (10-14) & 3254 & 562491 & 27.8621 & 1.3956 \\
Late adolescent (15-19) & 8912 & 1456350 & 72.1379 & 1.3956 \\
Total & 12166 & 2018841 & 100.000 &
\end{tabular}

Father's educational level

\begin{tabular}{|c|c|c|c|c|}
\hline Illiterate & 800 & 127821 & 6.33 & 0.32 \\
\hline Primary & 1793 & 294094 & 14.57 & 0.58 \\
\hline Intermediate & 1880 & 310794 & 15.40 & 0.48 \\
\hline High school & 2565 & 431574 & 21.38 & 0.47 \\
\hline University & 2424 & 399689 & 19.80 & 0.64 \\
\hline Graduate & 1204 & 206652 & 10.24 & 0.45 \\
\hline Do not know & 1497 & 247569 & 12.27 & 0.47 \\
\hline Total & 12163 & 2018192 & 100.00 & \\
\hline \multicolumn{5}{|l|}{ Mother's educational level } \\
\hline Illiterate & 1912 & 307534 & 15.21 & 0.52 \\
\hline Primary & 2382 & 396519 & 19.61 & 0.63 \\
\hline Intermediate & 1921 & 323951 & 16.02 & 0.42 \\
\hline High school & 2127 & 357926 & 17.70 & 0.47 \\
\hline University & 2041 & 338377 & 16.74 & 0.62 \\
\hline Graduate & 682 & 115237 & 5.70 & 0.29 \\
\hline Do not know & 1114 & 182324 & 9.02 & 0.35 \\
\hline Total & 12179 & 2021868 & 100 & \\
\hline \multicolumn{5}{|l|}{ Overall income } \\
\hline Less than US $\$ 2500$ & 3196 & 526930 & 49.63 & 1.07 \\
\hline Between US $\$ 2500$ and US\$USD & 1438 & 235861 & 22.22 & 0.59 \\
\hline More than US $\$ 4000$ & 1809 & 298835 & 28.15 & 1.09 \\
\hline Total & 6443 & 1061626 & 100.00 & \\
\hline \multicolumn{5}{|l|}{ Chronic illness } \\
\hline No & 10975 & 1821828 & 91.34 & 0.29 \\
\hline Yes & 1027 & 172796 & 8.66 & 0.29 \\
\hline Total & 12002 & 1994624 & 100.00 & \\
\hline \multicolumn{5}{|l|}{ Mental health } \\
\hline No & 10049 & 1663512 & 82.99 & 0.44 \\
\hline Yes & 2019 & 341043 & 17.01 & 0.44 \\
\hline Total & 12068 & 2004555 & 100.00 & \\
\hline \multicolumn{5}{|l|}{ Access to healthcare service } \\
\hline Difficult & 2917 & 482365 & 24.04 & 0.54 \\
\hline Easy & 9158 & 1523933 & 75.96 & 0.54 \\
\hline Total & 12075 & 2006297 & 100.00 & \\
\hline \multicolumn{5}{|l|}{ Sufficient time spent with physician } \\
\hline No & 3445 & 574633 & 39.08 & 0.59 \\
\hline
\end{tabular}




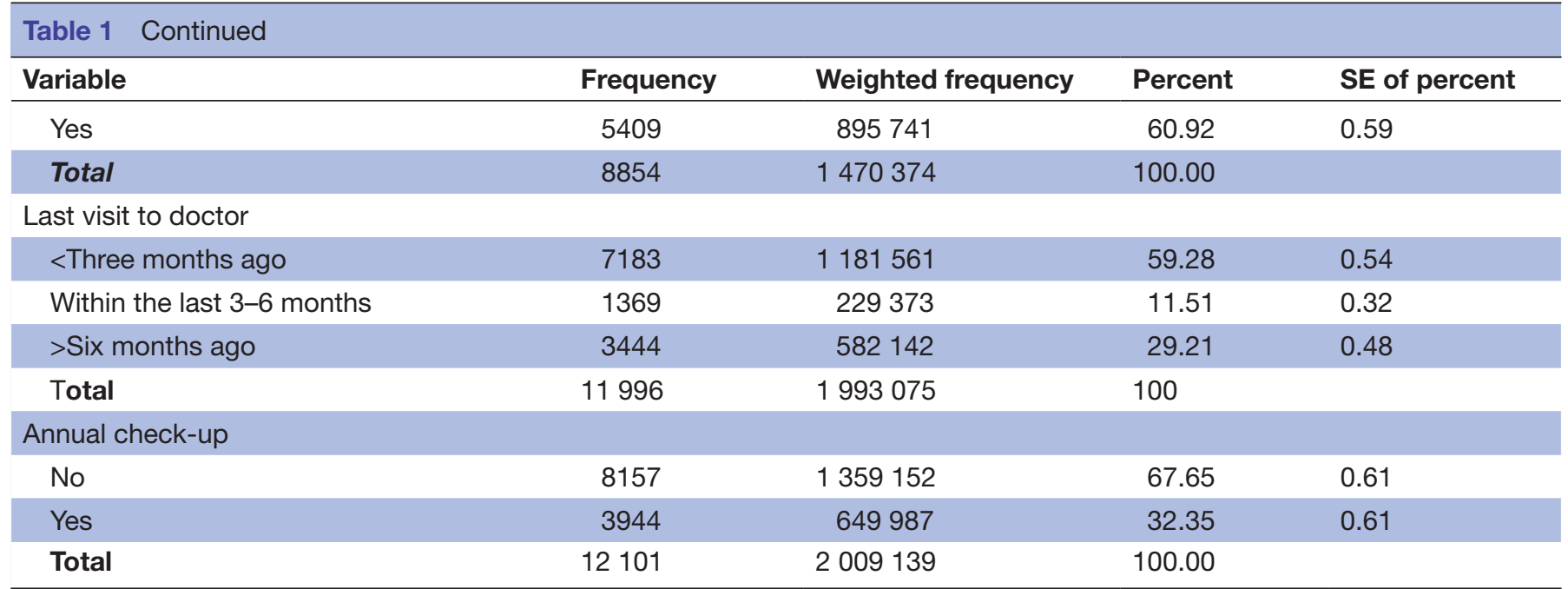

services at schools is an ideal and promising approach. ${ }^{23} 24$ Adolescent health services do not exist at KSA schools. Schools provide general health services run by primary healthcare providers not adolescents specialists. However, school health services will not serve adolescents who are out of school and who may have certain health needs and who are possibly facing inequality related to healthcare access. Having community-delivered health services for adolescents and linking these services with youth-serving organisations have been recommended to cover financially vulnerable adolescents. ${ }^{23} 25$

Interestingly, the findings suggest that women and early adolescents perceive themselves as having less difficulty in accessing healthcare compared with men and late adolescents. The results support previous findings on man and late adolescents' difficulties to access healthcare. ${ }^{26}{ }^{27}$ It is not easy for young men to accept and discuss their needs with health providers. They deny or do not acknowledge their health needs due to their development stage. ${ }^{28}$ This group requires special attention and access to services related to their biopsychosocial needs. ${ }^{8}$ Westwood and Pinzon ${ }^{26}$ highlight the importance of healthcare professionals being able to engage adolescent men in conversations in which the adolescent feels comfortable discussion issues of importance, other than the main health concern. In general, there is insufficient capacity for providers when it comes to addressing adolescent healthcare needs. To further add to this, there are male health issues, which may be underrecognised in KSA healthcare system as mental health. Training for healthcare professionals, especially school counsellors and school healthcare staff in male schools, could have a positive impact in closing the gap in access between adolescent males and females.

The findings reported herein revealed that adolescents with three siblings found it much easier to access healthcare compared with adolescents with no siblings. One possible explanation for this may be

Table 2 Sociodemographic, economic and health status factors associated with perceived difficulty in accessing healthcare

\begin{tabular}{|c|c|c|c|c|c|}
\hline Parameter & & OR & $\begin{array}{l}\text { Standard } \\
\text { error }\end{array}$ & $P$ value & $95 \% \mathrm{Cl}$ \\
\hline Intercept & & 0.44 & 1.31 & 0.003 & \\
\hline Gender & Female vs male & 0.81 & 1.10 & 0.021 & 0.68 to 0.97 \\
\hline Number of siblings & Four or greater vs no siblings & 0.64 & 1.29 & 0.082 & 0.39 to 1.06 \\
\hline \multirow[t]{2}{*}{ Overall income } & $<$ US $\$ 2500$ vs $>$ US $\$ 4000$ & 1.81 & 1.11 & $<0.0001$ & 1.48 to 2.22 \\
\hline & $\begin{array}{l}\text { Between US } \$ 2500 \text { and US } \$ 4000 \\
\text { vs }>\text { US } \$ 4000\end{array}$ & 1.25 & 1.12 & 0.056 & 0.99 to 1.58 \\
\hline Mental health & Yes vs no & 1.58 & 1.11 & $<0.0001$ & 1.29 to 1.94 \\
\hline
\end{tabular}

*Probability is modelled as 'Access to healthcare is difficult'.

†Significance is declared at alpha $<0.05$. 
that adolescents with more siblings have more experience and interaction with the healthcare system by the increased number of children in the household, and this may alter their perception to the ease of access to healthcare services compared with adolescents coming from single-child households.

Disparities in access to healthcare services for adolescents with mental or chronic illness were clearly identified in this study. These two groups had more difficulties in accessing health services than healthy adolescents. Attention to these subpopulations of adolescents, via providing them the services they need, through school health and primary care centres might improve their overall accessibility to health services. Raising awareness of needs may help to advance investment in expanding adolescent health and medicine services.

Older adolescents may have perceived poor access to care if they are attending adult healthcare systems after transition to adult services. Transferring these adolescents at a young age (12-14 years) to the adult healthcare system and providers often results in patients 'falling through the cracks' and losing follow-up with their providers. Their adult healthcare providers may not necessarily provide developmentally appropriate care, due to their different approach to healthcare. ${ }^{16}$ Moreover, adolescent health and medicine services should be available not only on a reflexive cure or management approach of disease but it should also provide health promotion and prevention services. ${ }^{25}$

\section{LIMITATIONS}

Several limitations of the present study should be acknowledged. First, the Jeeluna database did not allow us to differentiate between accessibility of community versus clinical healthcare settings. Second, adolescents not in school and those with special needs were not included in the study; their access to healthcare services and needs may differ. Since our study was crosssectional in nature, causality could not be inferred. However, our study highlights several factors that were associated with access to adolescent healthcare services and suggests interventions to improve accessibility. Moreover, anxiety, depression and chronic disease, as reported in our study, were based on self-report of existing symptoms or known chronic disease, respectively; they were not based on objective/formal assessments or documented clinical diagnoses. Therefore, these health conditions may be over or under estimated in our study. Furthermore, access to healthcare services as reported herein was assessed from an adolescent's perspective of how easy or difficult it is. Not only may adult/parents' perceptions differ, but access relative to available supply and demand as well as equity in the type of services was not assessed. Nonetheless, having this information, which is based on adolescents' perception of access reflects their needs/desires, which is of significance and may at times be overlooked.
As this study did not investigate the current needs of male and female adolescents, future studies should investigate the ability of an adolescent to access other existing services or studying the healthcare needs of adolescents especially for those with complex or mental health needs. Looking further at environmental determinants (like transportations and local variations in healthcare services supply, etc) of access to healthcare include a more in-depth analysis of the subgroups of adolescents, like male, who faced more challenges in accessing care are highly recommended to identify areas for improvement for access to adolescents' healthcare services.

\section{Author affiliations}

${ }^{1}$ Health Informatics, Arab American University, Ramallah, Palestinian Territory, Occupied

${ }^{2}$ Population Health Research Section, King Abdullah International Medical Research Center, Riyadh, Saudi Arabia

${ }^{3}$ King Abdullah International Medical Research Center, Riyadh, Riyadh, Saudi Arabia

${ }^{4}$ Barts Cancer Institute, London, UK

${ }^{5}$ Aldara Hospital and Medical Center, Riyadh, Riyadh, Saudi Arabia

${ }^{6}$ Johns Hopkins Bloomberg School of Public Health Center for Teaching and Learning, Baltimore, Maryland, USA

\section{Twitter Shahenaz Najjar @shnajjar}

Acknowledgements We acknowledge KAIMRC for their support and funding of the Jeeluna project. The study was approved by KAIMRC Institutional Review Board (IRB, RC08-092), as well as the Kingdom of Saudi Arabia's Ministry of Education. An abstract of this work was accepted at the Society for Adolescent Health and Medicine (SAHM) Annual Meeting 2018. The abstract was published in Journal of Adolescent Health 2018.

Contributors FA conceived the study, developed the methodology, obtained the research funding and necessary IRB approvals and contributed to the interpretation of the results. SN participated in the interpretation of results and contributed to writing the manuscript. SA contributed to writing the manuscript. MS performed the statistical analysis and interpretation of results. All authors participated in the manuscript outline, revised the manuscript critically for important intellectual content and read and approved the final manuscript. FA is the guarantor of the study.

Funding Funding for this study was obtained from the King Abdullah International Medical Research Centre (KAIMRC) (RC08-092). KAIMRC funding department did not have role in the design of the study, collection, analysis, interpretation of data or in writing the manuscript.

\section{Competing interests None declared.}

Patient and public involvement Patients and/or the public were not involved in the design, or conduct, or reporting, or dissemination plans of this research.

Patient consent for publication Not required.

Ethics approval IRB, RC08-092.

Provenance and peer review Not commissioned; externally peer reviewed.

Data availability statement Data are available upon reasonable request. The data that support the findings of this study are available from KAIMRC but restrictions apply to the availability of these data, which were used under license for the current study, and so are not publicly available. Data are however available from the authors upon reasonable request and with permission of KAIMRC.

Open access This is an open access article distributed in accordance with the Creative Commons Attribution Non Commercial (CC BY-NC 4.0) license, which permits others to distribute, remix, adapt, build upon this work non-commercially, and license their derivative works on different terms, provided the original work is properly cited, appropriate credit is given, any changes made indicated, and the use is non-commercial. See: http://creativecommons.org/licenses/by-nc/4.0/.

ORCID iD

Shahenaz Najjar http://orcid.org/0000-0002-4555-7713 


\section{REFERENCES}

1 Institute of Medicine (U.S). Committee on monitoring access to personal health care services. In: Millman ML, ed. Access to health care in America. National Academy Press, 1993.

2 Richard L, Furler J, Densley K, et al. Equity of access to primary healthcare for vulnerable populations: the impact international online survey of innovations. Int J Equity Health 2016;15:64.

3 O'Donnell O. Access to health care in developing countries: breaking down demand side barriers. Cad Saude Publica 2007;23:2820-34.

4 World Health Organization. Young people's health-a challenge for society. Report of a WHO Study Group on young people and "Health for All by the Year 2000. Geneva, 1986.

5 Kelishadi R, Overweight C. Childhood overweight, obesity, and the metabolic syndrome in developing countries. Epidemiol Rev 2007;29:62-76.

6 AlBuhairan FS, Tamim H, Al Dubayee M, et al. Time for an Adolescent Health Surveillance System in Saudi Arabia: Findings From "Jeeluna". J Adolesc Heal 2015;57:263-9.

7 AlBuhairan FS. Jeeluna® study: national assessment of the health needs of adolescents in Saudi Arabia. Riyadh: King Abdullah International Medical Research Center, 2016.

8 Ford CA, Bearman PS, Moody J. Foregone health care among adolescents. JAMA 1999;282:2227-34.

9 Institute of Medicine. Appendix E, guidelines for adolescent preventive services. Washington (DC: National Academies Press (US), 1997.

10 AlBuhairan F, Areemit R, Harrison A. Adolescent psychosocial development and evaluation: global perspectives. Complement. Pediatr., InTech, 2012.

11 WHO. WHO | global standards for quality health care services for adolescents. World Health Organization, 2015.

12 Macdonald NE. Adolescent access to healthcare. Paediatr Child Health 2003;8:551-2.

13 Cidro J, Suleman S, Leslie K. Adolescent health and nutrition in the US and Canada: an overview of issues and determinants. . Karger Publishers, 2014: 80. 27-48.

14 Ministry of Health. Statistical book for the Saudi Minstry of health, 2014.
15 Saudi Gov. 10. vision 2030, 2030. Available: http://www.vision2030. gov.sa/en/node [Accessed 01 Mar 2017].

16 AlBuhairan FS, Olsson TM. Advancing adolescent health and health services in Saudi Arabia: exploring health-care providers' training, interest, and perceptions of the health-care needs of young people. Adv Med Educ Pract 2014;5:281.

17 Almalki M, Fitzgerald G, Clark M. Health care system in Saudi Arabia: an overview. East Mediterr Health J 2011;17:784-93.

18 Sibley LM, Weiner JP. An evaluation of access to health care services along the rural-urban continuum in Canada. BMC Health Serv Res 2011;11:20

19 Banke-Thomas OE, Banke-Thomas AO, Ameh CA. Factors influencing utilisation of maternal health services by adolescent mothers in Low-and middle-income countries: a systematic review. BMC Pregnancy Childbirth 2017;17:65.

20 Collins SRC, McCarthy DM, Radley DCR. A Long Way in a Short Time: States' Progress on Health Care Coverage and Access, 201320152016.

21 Institute of Medicine (US) and National Research Council (US) Committee on the Science of Adolescence. The science of adolescent risk-taking: workshop report. Washington (DC), 2011.

22 United Nations Children's Fund (UNICEF). The state of the world's children 2011 adolescence an age of opportunity. New York, 2011.

23 Keeton V, Soleimanpour S, Brindis CD. School-Based health centers in an era of health care reform: building on history. Curr Probl Pediatr Adolesc Health Care 2012;42:132-56.

24 St Leger LH. The opportunities and effectiveness of the health promoting primary school in improving child health--a review of the claims and evidence. Health Educ Res 1999;14:51-69.

25 Brindis CD, Elizabeth Ozer PM, Handley M. Improving adolescent health an analysis and synthesis of health policy recommendations. San Francisco, 1997

26 Westwood M, Pinzon J. Adolescent male health. Paediatr Child Health 2008;13:31-6.

27 Bell DL, Breland DJ, Ott MA. Adolescent and young adult male health: a review state-of-the-art review article. Pediatr 2013;132:353-46.

28 Sandman D, Simantov E, An C. Out of touch: American Men and the health care system Commonwealth Fund Men's and Women's Health Survey Findings 2000. 